\title{
Attention deficit hyperactivity disorder (ADHD)
}

\author{
Fabio de Almeida Bolognani \\ Federação Brasileira de Homeopatia, Rio de Janeiro, Brazil
}

\begin{abstract}
The objective of this study, stated as Previous Notation, is to demonstrate that Attention Deficit Hyperactivity Disorder Pathology presents a differentiated condition in carriers where a significant percentage, close to $60 \%$, present a higher level of zinc elimination by kidneys. In this study, a direct relation of Zinc Mettalicum pathogenetic symptoms, this disturbance and the elimination of this element which participates in neurotransmission process were identified, and the relation with elements from regular diet, which can act as zinc chelating agents would be involved in the evolution of this disturbance, justifying the issue of individual susceptibility, essential in homeopathic investigation.
\end{abstract}

Keywords: Attention; Impulsivity; Agitation; Zincum Mettalicum; Neurotransmission.

Definition: Attention Deficit Hyperactivity Disorder is a neurological disorder, with probable genetic causes, which initiates during childhood and often accompanies the individual throughout his life, attenuated. It is characterized by symptoms such as INATTENTION, RESTLESSNESS and IMPULSIVE BEHAVIOR. It is a pathology identified by World Health Organization.

Prevalence: It is the most frequent disorder found in children and adolescents seeking specialized assistance. It is found at a 3 to $5 \%$ rate in child population. In more than half the cases, it accompanies the individual throughout adulthood, being more frequent in male population.

Signs and symptoms: Inattention / Hyperactivity / Impulsive Behavior.

Laboratory findings: Scientific studies point out alterations in frontal lobe and its cerebral connections. The frontal/orbital lobe is responsible for behavioral inhibition (controls or inhibits inadequate behaviors), ability to concentrate, memory, self-control, organization and planning. There are also references to neurotransmitters, such as dopamine and noradrenalin, and their connection with nervous cells.

Etiology: Hereditary causes, fetal suffering, lead exposure and family problems (unchaining factor) are frequently associated with clinical cases, but hypothesis such as yellow dyestuff, aspartame, artificial light, hormone deficiency (thyroid), and vitamin deficiencies are not confirmed.

Diagnosis: Using the diagnostic and statistical manual of mental disorders DSM-IV, we outline diagnostic criterion for Attention Deficit/Hyperactivity Disorder:

- Six or more of the following inattention symptoms that persist over at least six months:

\section{1- Inattention:}

- Frequently fails to pay attention to details or makes mistakes by carelessness in school activities, work, etc.

- Shows difficulty to maintain attention span during ludic tasks or activities.

- Frequently seems not to be listening when spoken to.

- Frequently will not follow instructions and will not complete school homework, domestic tasks or professional duties. 
- Frequently shows difficulty in organizing tasks and activities.

- Shows aversion or resists to involving himself in tasks that require constant mental effort (duties/tasks).

- Frequently looses objects needed to perform for activities or tasks such as toys, pencils, books, etc.

- Easily distracted by outer stimuli.

- Frequently forgets daily activities.

- Six of the following hyperactivity symptoms that persist over at least six months, in mal adaptive or inconsistent level with current development stage:

\section{2- Hyperactivity:}

- Shakes hands and feet or constantly moves around in the chair.

- Leaves his seat during classes or in other situations where he is expected to remain seated.

- Runs or climbs, in inappropriate situations.

- Demonstrates difficulties in silently playing or getting involved in leisure activities

- Always "plugged in", "at full speed".

- Talks too much

\section{3- Impulsiveness:}

- Frequently gives precipitated answers before questions have been fully posed.

- Has trouble waiting for his turn.

- Frequently interrupts or barges into other peoples' matters (play or conversation).

- Some hyperactivity, concentration and impulsivity symptoms that caused damage in their performance were present before the age of seven.

- Some of the damage in performance in two or more environments (school/work/home) was caused by symptoms.

- There must be uncontestable evidence of clinically significant loss to social, academic or occupational behavior.

- Symptoms do not occur exclusively during the course of a pervasive developmental disorder, schizophrenia, or other psychotic or mental alteration (anxiety disorder, dissociative disorder or personality disorders)

Treatment: Methylphenidate (Ritalin ${ }^{\circledR}$, Concerta ${ }^{\circledR}$, etc), amphetamine, imipramine, nortriptyline, desipramine, bupropion, clonidine, Homeopathy.

\section{(c) EY-NC-ND Licensed to GIRI}

Support: authors declare that this study received no funding

Conflict of interest: authors declare there is no conflict of interest

Correspondence author: Fabio de Almeida Bolognani, fabiobolognani@gmail.com

How to cite this article: Bolognani FA. Attention deficit hyperactivity disorder (ADHD). Int J High Dilution Res [online] 2011 [cited YYYY Month dd]; 10(35): 82-83. Proceedings of the XXIV GIRI Symposium; 2010 Nov 05; Monte Carlo (Monaco). GIRI; 2010. Available from: http://www.feg.unesp.br/ ojs/index.php/ijhdr/article/view/442/474 